\title{
BMJ Open Physiotherapy after anterior cervical spine surgery for cervical disc disease: study protocol of a prospective randomised study to compare internet- based neck-specific exercise with prescribed physical activity
}

\author{
Anneli Peolsson, ${ }^{1}$ Gunnel Peterson, ${ }^{1,2}$ Anna Hermansen, ${ }^{1}$ \\ Maria Landén Ludvigsson,, ${ }^{1,3}$ Åsa Dedering, ${ }^{4,5}$ Håkan Löfgren ${ }^{6}$
}

To cite: Peolsson A, Peterson G, Hermansen A, et al. Physiotherapy after anterior cervical spine surgery for cervical disc disease: study protocol of a prospective randomised study to compare internet-based neck-specific exercise with prescribed physical activity. BMJ Open 2019;9:e027387. doi:10.1136/ bmjopen-2018-027387

- Prepublication history for this paper is available online. To view these files, please visit the journal online (http://dx.doi. org/10.1136/bmjopen-2017027387).

Received 23 0ctober 2018 Revised 12 November 2018 Accepted 16 November 2018

Check for updates

(C) Author(s) (or their employer(s)) 2019. Re-use permitted under CC BY-NC. No commercial re-use. See rights and permissions. Published by BMJ.

For numbered affiliations see end of article.

Correspondence to Professor Anneli Peolsson; Anneli.Peolsson@liu.se

\begin{abstract}
Introduction Patients suffering from remaining disability after anterior cervical decompression and fusion (ACDF) surgery for cervical disc disease may be prescribed physical activity (PPA) or neck-specific exercises (NSES). Currently, we lack data for the success of either approach. There is also a knowledge gap concerning the use of internet-based care for cervical disc disease. The scarcity of these data, and the high proportion of patients with various degrees of incapacity following ACDF, warrant increased efforts to investigate and improve cost-effective rehabilitation. The objective is to compare the effectiveness of a structured, internet-based NSE programme, versus PPA following ACDF surgery.
\end{abstract}

Methods and analysis This is a prospective, randomised, multicentre study that includes 140 patients with remaining disability ( $230 \%$ on the Neck Disability Index, NDI) following ACDF for radiculopathy due to cervical disc disease. Patient recruitment occurs following attendance at routine clinical appointments, scheduled at 3 months postsurgery. Patients are then randomised to one of two groups (70 patients/group) for a 3-month treatment programme/period of either internetbased NSE or PPA. Questionnaires on background data, pain and discomfort, physical and mental capacity, satisfaction with care, and health and workplace factors are completed, along with physical measures of neck-related function conducted by independent test leaders blinded to randomisation. Measures are collected at inclusion, after the 3-month treatments (end of treatment) and at a 2-year follow-up. Radiography will be completed at the 2-year follow-up. Preoperative data will be collected from the Swedish Spine Registry. Data on healthcare consumption, drug use and sick leave will be requested from the relevant national registers.

Ethical considerations This study was approved by the Regional Ethical Review Board in Linköping Ref. 2016/283-31 and 2017/91-32. The scientists are independent with no commercial ties. Patients are recruited after providing written informed consent. Patient data are presented at group level such that no connection to any individual can be made. All data are anonymised when reported, and subject to the Swedish Official Secrets Health Acts. The test leaders are independent and blinded for randomisation. Exercises, both
Strengths and limitations of this study

- The present internet-based treatment is new and innovative, and the study findings may contribute to the development of a more effective rehabilitation for those with residual disability after anterior cervical decompression and fusion.

- The study is a prospective randomised controlled study with test leaders/assessors blinded for randomisation and not involved in the treatment of the participants.

- The results from a multicentre study may be more generalisable than a one-site study and may also enhance implementation in outpatient clinical practice.

- A multicentre study offers less control of the interventions provided.

- Access to a computer/smartphone/tablet is needed for study participation which may exclude some individuals, although about $95 \%$ of Swedish people have access to a computer/smartphone/tablet and the internet.

general and neck-specific, have been used extensively in clinical practice and we anticipate no harm from their implementation other than a risk of muscle soreness. Both randomisation groups will receive care that is expected to relieve pain, although the group receiving NSE is expected to demonstrate a greater and more cost-effective improvement versu s the PPA group. Any significant harm or unintended effects in each group will be collected by the test leaders. All questionnaires and test materials are coded by the research group, with code lists stored in locked, fireproof file cabinets, housed at the university in a room with controlled (card-based) access. Only individuals in receipt of a unique website address posted by the researchers can access the programme; patients can neither communicate with each other nor with caregivers via the programme. Study participation might lead to improved rehabilitation versus non-participation, and might therefore be of benefit. The results of this study should also 
contribute to more effective and flexible rehabilitation, shorter waiting times, lower costs and the possibility to implement our findings on a wider level.

Dissemination If effective, the protocols used in this study can be implemented in existing healthcare structures. The results of the study will be presented in scientific journals and popular science magazines of relevance to health. The findings will also be presented at local, regional, national and international conferences and meetings, as well as in the education of university students and at public lectures. Information about the results will be communicated to the general population in cooperation with patient organisations and the media.

Trial registration NCT03036007.

\section{INTRODUCTION}

\section{Radiculopathy due to cervical disc disease and its treatment}

Anterior cervical decompression and fusion (ACDF) is an established method with which to treat radiculopathy for cervical disc disease, ${ }^{1-3}$ with several studies reporting favourable results that include reduced pain and neurological involvement, and a largely satisfied $(80 \%)$ patient cohort. ${ }^{3}$ However, results from more detailed evaluations that include functional ability have been less optimistic, ${ }^{14-11}$ with approximately two-thirds of patients reporting poor self-rated neck-specific function, low neckmuscle endurance, daily neck pain, mental illness and low health-related quality of life. ${ }^{4-12}$ Three months after surgery $40 \%$ have a Neck Disability Index (NDI) rating of $30 \%$ or above, changing to $36 \%$ at 2-year follow-up (Peolsson et al, statistical analyses, Linköping University 7 March 2018). The majority of studies have focused on surgical technique rather than function or rehabilitation.

While ACDF on one or more segmental levels can be expected to reduce (specific) disc-related symptoms, it will not necessarily improve non-specific neck pain, or relieve disability/illness. Therefore there is an urgent need to investigate whether postoperative physical therapy may improve outcomes for those with remaining disability after ACDF.

Ideally, in studies of patients with radiculopathy due to cervical disc disease, their diagnosis should be confirmed by MRI (ie, clinical examination combined with consistent findings from MRI). ${ }^{8}{ }^{13-17}$ However, few studies have investigated the success of physiotherapy for these 'verified' patients. Persson et al, ${ }^{13}$ in comparing ACDF surgery with physiotherapy and the use of a neck collar, reported no differences between the treatment strategies 15 months after enrolment. Peolsson $e t a l^{8}$ and Engquist et $a l^{17}$ evaluated the benefits of ACDF beyond structured physiotherapy, by incorporating neck-specific exercises (NSEs) with a behavioural medicine approach. Besides reduced neck pain, no significant differences between the groups were identified at the 2-year follow-up. ${ }^{817} \mathrm{~A}$ follow-up of 5-8 years after intervention revealed that selfrated pain and neck-specific function were significantly better for the group that had received surgery versus those having received physical therapy alone. ${ }^{18}$ That study concluded that structured physiotherapy should precede any decisions on ACDF. ${ }^{817}$ One study ${ }^{19-21}$ comparing structured NSE in combination with a behavioural medicine approach versus standard care (necessitating that patients proactively seek physiotherapy in primary healthcare settings) showed that those who completed structured rehabilitation reported a lower incidence of neck pain and were more satisfied with their care, with expectations of treatment that were more likely to be met. Although unique and innovative, design problems in the study ${ }^{19-21}$ included a random preoperative assignment to postoperative rehabilitation. This led to patients who felt well after surgery failing to report further improvements after physiotherapy, whereas those with postoperative complications were unable to complete their (planned) rehabilitation. Further, the structured rehabilitation was extensive, involving 30 visits to the physiotherapy clinic (optimally), which led to adherence difficulties (ie, problems fitting these physiotherapy visits into a busy work schedule). Ultimately, the majority (approximately $60 \%$ ) of the patients randomised to standard care ${ }^{2021}$ sought physiotherapy, demonstrating its need in postoperative rehabilitation, although this was ultimately a 'confounding factor ${ }^{20} 21$ given its lack of standardisation.

\section{Internet-based care}

Healthcare providers are facing substantial challenges, with care provision needing to evolve and improve in the face of increased demand and fiscal pressures. Consequently, new ways of providing healthcare should be investigated for their utility in increasing availability, reducing waiting times and costs, and increasing patient adherence, especially for those needing long-term physiotherapy. Equivalent or even improved efficacy for internet-based treatment versus face-to-face intervention with caregivers has already been demonstrated for a number of conditions, ${ }^{22-28}$ but not post-ACDF. Combining a few caregiver visits with internet-based support ${ }^{29}$ should safeguard quality of care, while ensuring that exercises are being performed correctly.

\section{Knowledge gaps for physiotherapy after ACDF}

Multiple knowledge gaps exist. These include studies on: post-ACDF rehabilitation for individuals with residual disability; effect of postoperative NSE as a stand-alone treatment (in addition to advice/regimen recommended at surgical clinics) or prescribed physical activity (PPA). We also lack information on: muscle function following ACDF, work capacity or the cost benefits of rehabilitation post-ACDF, internet-based care for long-standing neck pain inclusive of cervical disc disease and postoperative rehabilitation. The high proportion of patients with residual problems after ACDF suggests an unmet need for evidence-based rehabilitation designed to improve future care.

\section{Purpose}

The main purpose of the study is to investigate whether internet-based, structured NSE differs from PPA after surgery for cervical disc disease, in relation to function, pain, work capacity, health-related quality of life, 


\begin{tabular}{|c|c|c|c|c|c|c|}
\hline \multirow[b]{3}{*}{ TIMEPOINT * } & \multicolumn{6}{|c|}{ STUDY PERIOD } \\
\hline & \multirow{2}{*}{$\begin{array}{c}\text { Enrollment } \\
0\end{array}$} & \multirow{2}{*}{$\begin{array}{c}\text { Allocation } \\
0\end{array}$} & \multicolumn{3}{|c|}{ Post-allocation } & \multirow{2}{*}{$\begin{array}{c}\begin{array}{c}\text { Close- } \\
\text { out }\end{array} \\
t_{x}\end{array}$} \\
\hline & & & $\mathbf{t}_{1}$ & $\mathbf{t}_{2}$ & $\mathbf{t}_{3}$ & \\
\hline \multicolumn{7}{|l|}{ ENROLLMENT } \\
\hline Eligibility screen & $\mathrm{X}$ & & & & & \\
\hline Informed consent & $\mathrm{X}$ & & & & & \\
\hline Allocation & & $\mathrm{X}$ & & & & \\
\hline \multicolumn{7}{|l|}{ INTERVENTIONS ** } \\
\hline $\begin{array}{l}\text { Internet-based neck-specific } \\
\text { exercises }\end{array}$ & & & $\mathrm{X}$ & $\mathrm{X}$ & $\mathrm{X}$ & \\
\hline Prescribed physical activity & & & $\mathrm{X}$ & $\mathrm{X}$ & $X$ & \\
\hline \multicolumn{7}{|l|}{ ASSESSMENTS $* * *$} \\
\hline Demographic data & $\mathrm{X}$ & & $\mathrm{X}$ & & & \\
\hline $\begin{array}{l}\text { Self-reported outcomes } \\
\text { (questionnaires) }\end{array}$ & & & $X$ & $\mathrm{X}$ & $X$ & $\mathrm{X}$ \\
\hline Clinical outcomes & & & $\mathrm{X}$ & $\mathrm{X}$ & $\mathrm{X}$ & $\mathrm{X}$ \\
\hline
\end{tabular}

* $t_{1}=$ baseline, $t_{2}=3$ month follow-up (end of intervention in the study), $t_{3}=24$ month follow-up. $t_{x}=24$ month follow-up (21 months post intervention).

** Internet-based neck-specific exercises $=12$ weeks of neck-specific exercises with 4 appointments at physiotherapy clinic + internet support. Prescribed physical activity $=12$ weeks of general exercises with 4 appointments at physiotherapy clinic.

*** Questionnaires on various aspects on disability, pain, psychosocial factors etc. including the main outcome Neck Disability Index. Clinical outcome measures including neck muscle endurance, range of motion, neurological tests etc.

Figure 1 The Standard Protocol Items: Recommendations for Interventional Trials schedule of enrolment, interventions and assessments.

satisfaction with care and cost effectiveness. Additional analyses may be performed.

\section{Hypothesis}

The hypothesis is that internet-based NSE will be superior to PPA in terms of primary outcome of NDI and secondary measures. The project is expected to lead to improved care, well-being and patient satisfaction.

\section{Methods and analysis \\ Design}

This is a prospective, randomised, experimental longitudinal multicentre study performed in Sweden, with a 2-year follow-up (figures 1 and 2). Questionnaires are distributed and physical tests are collected at baseline, at the end of treatment (3 months after enrolment) and after 2 years. Preoperative data are collected from the Swedish spine registry, Swespine. Patients are recruited from the surgical unit at the time of regular follow-up visits to the physiotherapist/surgeon at approximately 3 months postoperatively (figures 1 and 2).

When the study criteria is met, and written and oral informed consent has been provided, the patient completes a questionnaire and undergoes physical measures of neck-related function. The patient is then randomised to one of two groups for 3 months of treatment with (1) Internet-based NSE with four visits to the physiotherapist or (2) PPA with four visits to the physiotherapist. The computerised block randomisation list is compiled by a statistician and the randomisation is stratified for gender with the aim of achieving equal numbers of men and women in the treatment groups. Patients in both groups are examined by a physiotherapist at the first visit in accordance with Swedish law.

The test leader is a physiotherapist at the surgical unit (obtains the written informed consent from the 


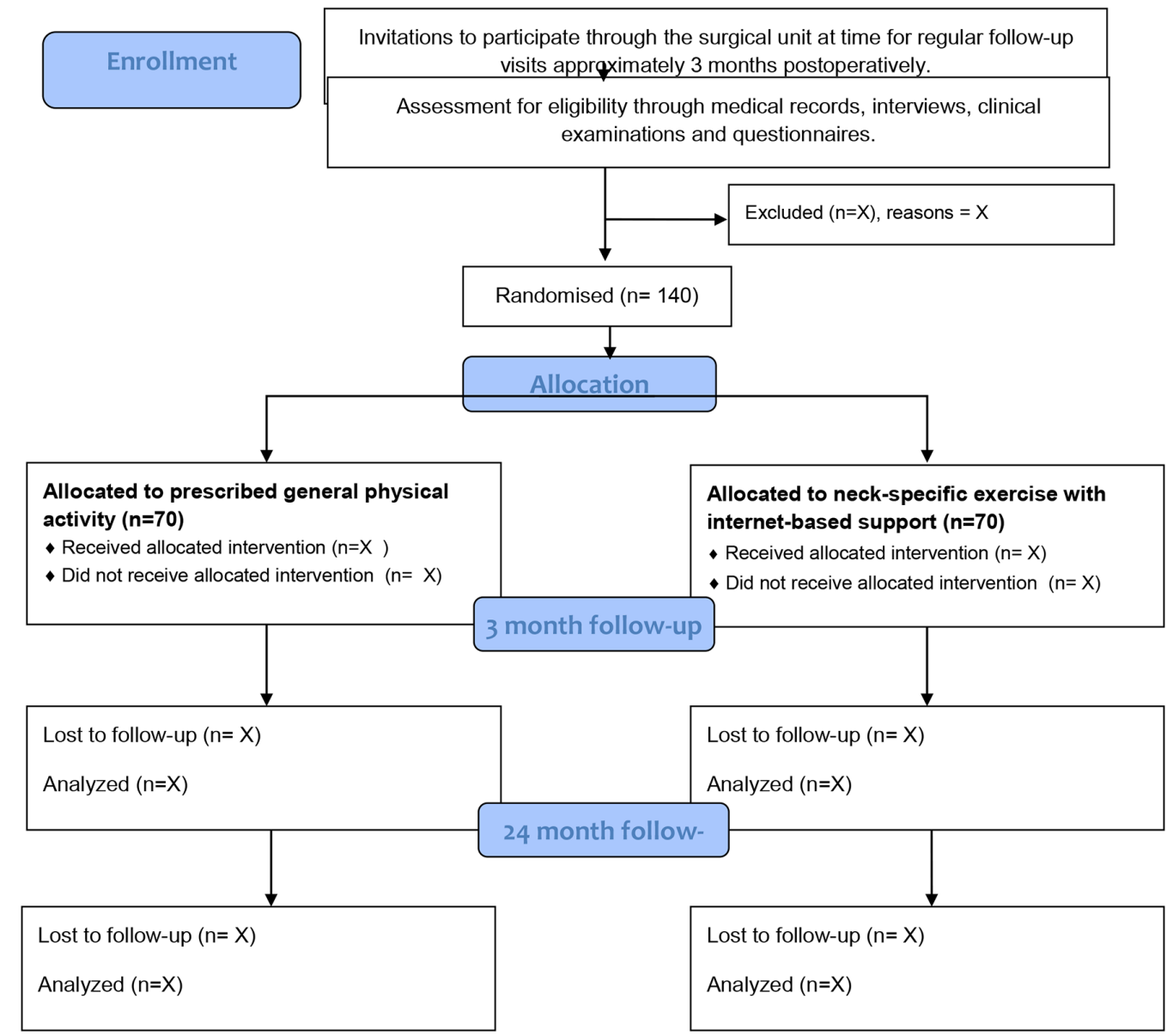

Figure 2 The Consolidated Standards of Reporting Trials flow diagram for 'Physiotherapy after anterior cervical spine surgery for cervical disc disease'.

study participant) who is not involved in study treatment and is blinded to the randomisation groups. Following randomisation, the results will be put into an opaque envelope that contains the name of the patient and their randomisation group, which is sent to the relevant physiotherapy outpatient care clinic. Questionnaires and tests of physical neck-related function are conducted at baseline (before randomisation), after 3 months (when the treatment ends) and after 2 years (figures 1 and 2). Participating physiotherapists will be provided with oral, written and practical training, and are able to consult project managers at any time. Exercise diaries and the number of care contacts will be recorded for both groups. Recruitment started on 14 February 2018.

\section{Study criteria}

Assessment for eligibility was conducted through preoperative recordings in Swespine by the surgical department, supplemented with medical records, questionnaires, interviews and clinical examinations.

\section{Inclusion criteria}

Preoperative criteria: cervical disc disease (disc herniation with or without osteophytes, or stenosis caused by osteophytes) in one or two segmental levels, confirmed by MRI data compatible with clinical findings (neurological examination performed by a neck surgeon, ie, a neurosurgeon/orthopaedic surgeon) of nerve root compression in the cervical spine; radiculopathy with pain in one or both arms, with or without sensory and/ or motor deficit; ACDF; at least 3 months of persistent arm pain; age 18-75 years. Postoperative criteria: remaining disability (approximately) 3 months after surgery (at the revisit to the surgeon/physiotherapist at the neurosurgery/neuro-orthopaedic clinic) in terms of an $\mathrm{NDI}^{30}{ }^{31}$ Score of $\geq 30 \%$; access to a computer/ tablet/smartphone and the internet; motivated to exercise.

\section{Exclusion criteria are as follows}

Myelopathy; previous fracture or dislocation of the cervical spine; malignancy or benign spinal tumour (eg, neuromas); spinal infection; ongoing postoperative infection, or previous spondylodiscitis; previous cervical spine surgery; factors that are contraindicated for study participation or which hinder treatment or follow-up because of systemic disease, physical or mental illness, injury, inconvenience or postoperative complications; known alcohol/ drug abuse; lack of ability to write/comprehend/express oneself in Swedish. 


\section{Patient and public involvement}

The internet intervention programme and the questionnaires were pilot tested by people with neck pain before the study started and thereafter revised. Included in the questionnaires are specific questions regarding the experience of participating in the study, as well as their experiences of completing the questionnaires. A subgroup may also be interviewed regarding their expectations and experiences of participating in the intervention. The results of the study will be disseminated to patients through media and public conferences.

\section{Intervention}

NSEs are used due to their reported efficacy in reducing pain, and in improving function and health. ${ }^{32-38}$ General physical activity (PPA) has also been shown to alleviate chronic pain ${ }^{39}$ and is recommended for patients with neck pain. ${ }^{40}$ It is recommended that participants not receive other physiotherapy intervention for their neck problems during the present study participation.

\section{Internet-based NSES}

Participants will be provided with an explanation of their exercises and the objectives of these. The programme includes exercises to activate the deep neck muscles (initially daily), continuing with endurance training of the neck and shoulder muscles (three times/week for 12 weeks) (https://liu.se/en/employee/annpe35).

Exercises will be tailored to the individual's physical condition, and then scaled up progressively in terms of degree of difficulty and dose. Participants will undertake four visits to the physiotherapist (including the mandatory first visit for new clinical assessment as required by Swedish law), where the exercises will be introduced and repeated in order to establish and enable patient comprehension. The exercises are completed with the help of internet support outside of the healthcare system, which can be accessed anywhere, but most probably at home. Photos and videos of the exercises, information and answers to frequently asked questions are available on the internet-support platform. At the end of the treatment period, the patients are encouraged to continue practising the exercises on their own.

\section{Prescribed physical activity}

The training consists of general physical activity (three times/week for 12 weeks). ${ }^{42} 43$ The aim is to find a physical activity outside of the care unit that suits the individual, based on their specific needs and problems. The goal is that the individual should increase their overall level of physical activity, and that this activity is performed as part of a self-care/wellness routine. This may involve activities that can be performed at home, such as walking according to a set schedule, home exercises given by a physiotherapist (not neck-specific training), aerobic classes, and so on. To increase adherence, a motivational interview is conducted before the PPA schedule is provided. Patients are advised to contact the physiotherapist if their prescribed activity is no longer suitable so that another activity can be identified. Four visits to the physiotherapist are provided (after the mandatory first visit for new clinical assessment), with the patient being encouraged to continue practising on their own at the end of the treatment period.

\section{Outcome measures}

Background data that will be collected include: surgery-related data including the number and segmental levels treated, surgical complications and reoperations during follow-up. Data regarding age, sex, symptom duration and onset, education, occupation, smoking, marital status, drug consumption, previous treatments and expectations of future treatment will be collected.

Primary main outcome measure: neck-specific functioning as measured by the NDI percentage score (0\%-100\%, where $0 \%$ denotes optimal function).$^{30} 31$

Secondary outcome measures that will be collected include: pain intensity of the neck, arm and head, measured using the Visual Analogue Scale (VAS $0-100 \mathrm{~mm}) ;^{44}$ pain intensity for the neck and arm will also be assessed and registered using the numeric rating scale (NRS) 0-10 Scale $^{45}$ in line with the Swespine registry; pain frequency with a 5-point scale (never=1, constantly=5); pain drawing, an innovative new technology where painful areas are shaded on a human body image (male or female) using a tablet for instant digital computing, 'the Pain Sketch app'; ${ }^{46}$ registration of the use of pain medications; global perceived effect (modified Odom), on a 6-point scale (restored/much better to much worse) $;^{47}$ dizziness/balance; Dizziness Handicap Inventory Scale ${ }^{48}$ and $\mathrm{VAS}^{49}$ headache questions (the headache impact test and VAS) ${ }^{44} 49$ catastrophising; the Pain Catastrophising Scale (PCS) $;{ }^{50}$ confidence in one's own ability; Self-Efficacy Scale $;^{51}$ estimation of neck-specific function related to participants' chosen activities (daily function, work, spare time); Patient-Specific Functional Scale; ${ }^{52}$ operating fear; Fear Avoidance Beliefs Questionnaire; ${ }^{53} 54$ depression, anxiety; Hospital Anxiety and Depression Scale $;^{55}$ health-related quality of life; EuroQuol and EQ thermometer $;{ }^{56}$ self-rated work; Work Ability Index, short form; ${ }^{57-59}$ requirements-effort support in the workplace: Effort Reward Imbalance; ${ }^{60}$ ergonomics questions; sickness presence (Stanford Presenteeism Scale) ${ }^{61}{ }^{62}$ Swedish Standard Classification of Occupations (SSY) code ${ }^{63}$ expectations met and satisfaction with care; Cherkin symptom satisfaction; ${ }^{64}$ Patient Enablement Instrument and VAS; ${ }^{65}$ level of physical activity; Score $0-4 ;{ }^{66}{ }^{67}$ care consumption, exercise diary, sick days recorded. Sick data are also retrieved from the social insurance MiDAS register. Care consumption and medical prescriptions ordered through the healthcare databases of each region are used in cost-effectiveness analyses.

Tests conducted by the test leader will be: neck movement measured using the cervical range of motion device in degrees $;{ }^{68}$ endurance in the dorsal and ventral neck 
muscles, measured in seconds; ${ }^{67}$ sensorimotor control of ventral neck muscles, in the supine position, with stabiliser $(\mathrm{mm} \mathrm{Hg}) ;{ }^{69}$ examination of the sensation, force and reflexes in the arm/hand, nerve tension test, Spurling's test and manual examination/palpation of neck structures and movement in the upper cervical spine; ${ }^{70}$ hand strength measured with a hand dynamometer; ${ }^{71}$ balance test, standing on one leg with eyes closed (Solec test) ${ }^{72}$ conventional radiography, with side views taken during neutral positioning and dynamic flexion/extension, as carried out routinely at the clinic for visits 3 months after surgery to examine implants and the degree of mobility of operated segments. Additional radiography will be taken at the 2-year follow-up to investigate fusion as well as possible subsidence of the cervical spine segment. In the event of pregnancy, radiography will be postponed until after birth (the extra X-ray examination was approved by the respective hospitals' radiation protection committee); data collected from national or regional registries: register data from Swespine, which provides the opportunity to follow participants over time (preoperatively, and then 1 year, 2 years, 5 years and 10 years postoperatively); register data for care use. To measure/monitor care use, the National Board of Health and Welfare patient register will be used, which collates all inpatient and outpatient care at hospitals, including operations and measures to be used. To follow patients' consumption of painkillers and antidepressants, the national Prescribed Drug Register will be consulted. To report those lost to follow-up, the Cause of Death Register and Statistics Sweden will be consulted, with variables on immigration and emigration checked. For data on sick leave, income, education, and so on, the LISA database (National Statistical Central Bureau) will be used (http://www.socialstyrelsen. se/register) (http://www.scb.se/en/services/guidancefor-researchers-and-universities/vilka-mikrodata-finns/ longitudinella-register/longitudinal-integration-database-for-health-insurance-and-labour-market-studieslisa/). Data on sick leave can also be requested from the Social Insurance Agency. Any important harms or unintended side effects will be collected by the test leaders, and adherence to treatment by an exercise diary.

\section{Sample size calculation and statistics}

Sample size calculations (conducted by a statistician) were based on a between-group difference of 10 score units in the primary outcome measure NDI (NDI percentage score).

Seventy participants per group are needed (assuming $80 \%$ power, and a level of significance of $5 \%$ ), that is, a total of 140 participants are required. This calculation is based on group differences recorded in previous studies. ${ }^{171832337374}$

As we lack any studies on rehabilitation for patients with remaining disability after ACDF, this calculation remains hypothetical and our sample size may need to be adjusted. This number can also be adjusted in the event of participants dropping out, such that at least 70 individuals per group complete the intervention. Data will be analysed using an intention-to-treat approach. Additional analyses will be carried out where the degree of implementation of treatment (adherence) is taken into account, as well as gender, dizziness, headaches, neurological findings and the number of segmental levels operated on. Analyses will be performed using parametrical or non-parametrical statistics, depending on the type of data, in consultation with statisticians as appropriate.

\section{Trial limitations}

The present study is a multicentre study, involving multiple treating therapists in several cities. This design offers less control of the interventions provided. To improve control, the treating physiotherapists will be educated by the project leaders and will have sufficient time to practise the standardised interventions in preparation for the study. Patients also follow exercise programmes within a standardised frame, which increases the similarity in intervention/information provided. Exercise diaries will be used in both randomisation groups to better control the intervention. The results from a multicentre study may be more generalisable than a single-site study because they will not depend on a single physiotherapist's knowledge, enthusiasm and charisma and may also enhance implementation in outpatient clinical practice. Access to a computer/smartphone/tablet is needed for study participation. Today, most people in both younger and older age groups have access to such devices and an internet connection. ${ }^{75}$ To be able to complete the questionnaires and to understand the internet-based programme, participants need to speak and understand Swedish. If the results of the internet-based programme are successful, the web-based programme can be translated into other languages for wider implementation.

\section{Collaboration}

The research team will have access to the final data set. We are open to collaboration with others; please contact the principal investigator (AP) for scientific discussions.

\section{Author affiliations}

${ }^{1}$ Department of Medical and Health Sciences, Physiotherapy, Linköping University, Linköping, Sweden

${ }^{2}$ Centre for Clinical Research Sörmland, Uppsala University, Uppsala, Sweden ${ }^{3}$ Department of Rehabilitation and Department of Medical and Health Sciences, Rehab Väst, Region Council of Östergötland, Linkoping, Sweden

${ }^{4}$ Allied Health Professionals Function, Occupational Therapy and Physiotherapy, University Hospital, Stockholm, Sweden

${ }^{5}$ Department of Neurobiology, Care Sciences and Society, Division of Physiotherapy, Karolinska Institutet, Stockholm, Sweden

${ }^{6}$ Neuro-Orthopedic Center, Ryhov Hospital, Jönköping, Sweden

Acknowledgements The authors thank all county councils and physiotherapists that will be involved. The authors also thank patient advisers for their valued opinions on the internet-based programme as well as the questionnaires before the study started.

Contributors Overall scientific idea: AP; idea of using register data: ÅD; project planning: AP, HL, GP, AH; development of the web system: AP, GP; project coordinator: AH, AP; manuscript writing: AP with support from the other authors; 
manuscript revision: AP, HL, GP, AH, MLL, ÅD. All authors approved the final version. Primary investigator: AP.

Funding This study is supported by funding from the regional Center for Clinical Research and the Region Council of Östergötland County (received in competition). Additional funding will be applied for. Sponsors may communicate trial results on governmental or county council websites.

Competing interests None declared.

Patient consent for publication Obtained.

Ethics approval Regional Ethical Review Board in Linköping Ref. 2016/283-31 and 2017/91-32

Provenance and peer review Not commissioned; externally peer reviewed.

Open access This is an open access article distributed in accordance with the Creative Commons Attribution Non Commercial (CC BY-NC 4.0) license, which permits others to distribute, remix, adapt, build upon this work non-commercially, and license their derivative works on different terms, provided the original work is properly cited, appropriate credit is given, any changes made indicated, and the use is non-commercial. See: http://creativecommons.org/licenses/by-nc/4.0/.

\section{REFERENCES}

1. Löfgren $\mathrm{H}$. Outcome and bone grafts in surgical treatment of cervical disc disease. Linköping University Medical Dissertations, Sweden. 2000. ISSN 0345-0082;6212000, ISBN:91-7219-578-9 http://liu.divaportal.org/smash/record.jsf?pid=diva2:248610.

2. Epstein NE. A review of laminoforaminotomy for the management of lateral and foraminal cervical disc herniations or spurs. Surg Neurol 2002;57:226-33.

3. Hacker RJ, Cauthen JC, Gilbert TJ, et al. A prospective randomized multicenter clinical evaluation of an anterior cervical fusion cage. Spine 2000;25:2646-55

4. Peolsson A, Kjellman G. Neck muscle endurance in nonspecific patients with neck pain and in patients after anterior cervical decompression and fusion. J Manipulative Physiol Ther 2007;30:343-50.

5. Peolsson A. Investigation of clinically important benefit of anterior cervical decompression and fusion. Eur Spine J 2007;16:507-14

6. Zoëga B, Kärrholm J, Lind B. Outcome scores in degenerative cervical disc surgery. Eur Spine J 2000;9:137-43.

7. Peolsson A, Peolsson M. Predictive factors for long-term outcome of anterior cervical decompression and fusion: a multivariate data analysis. Eur Spine J 2008;17:406-14.

8. Peolsson A, Söderlund A, Engquist M, et al. Physical function outcome in cervical radiculopathy patients after physiotherapy alone compared with anterior surgery followed by physiotherapy: a prospective randomized study with a 2-year follow-up. Spine 2013;38:300-7

9. Hermansen A, Hedlund R, Vavruch L, et al. A comparison between the carbon fiber cage and the cloward procedure in cervical spine surgery: a ten- to thirteen-year follow-up of a prospective randomized study. Spine 2011;36:919-25.

10. Peolsson A, Vavruch L, Hedlund R. Long-term randomised comparison between a carbon fibre cage and the Cloward procedure in the cervical spine. Eur Spine J 2007;16:173-8.

11. Peolsson A, Vavruch L, Oberg B. Can the results 6 months after anterior cervical decompression and fusion identify patients who will have remaining deficit at long-term? Disabil Rehabil 2006;28:117-24.

12. Peolsson A, Vavruch L, Öberg B. Disability after anterior decompression and fusion for cervical disc disease. Adv Physiother 2002;4:111-24

13. Persson LC, Carlsson CA, Carlsson JY. Long-lasting cervical radicular pain managed with surgery, physiotherapy, or a cervical collar. A prospective, randomized study. Spine 1997;22:751-8.

14. Ellenberg MR, Honet JC, Treanor WJ. Cervical radiculopathy. Arch Phys Med Rehabil 1994;75:342-52.

15. Murphy DR, Hurwitz EL, Gregory A, et al. A nonsurgical approach to the management of patients with cervical radiculopathy: a prospective observational cohort study. J Manipulative Physiol Ther 2006;29:279-87.

16. Saal JS, Saal JA, Yurth EF. Nonoperative management of herniated cervical intervertebral disc with radiculopathy. Spine 1996;21:1877-83.

17. Engquist $M$, Löfgren $H$, Öberg $B$, et al. Surgery versus nonsurgical treatment of cervical radiculopathy: a prospective, randomized study comparing surgery plus physiotherapy with physiotherapy alone with a 2-year follow-up. Spine 2013;38:1715-22.
18. Engquist M, Löfgren $\mathrm{H}$, Öberg $\mathrm{B}$, et al. A 5- to 8-year randomized study on the treatment of cervical radiculopathy: anterior cervical decompression and fusion plus physiotherapy versus physiotherapy alone. J Neurosurg Spine 2017;26:19-27.

19. Peolsson A, Öberg B, Wibault J, et al. Outcome of physiotherapy after surgery for cervical disc disease: a prospective randomised multi-centre trial. BMC Musculoskelet Disord 2014;15:34.

20. Wibault J, Öberg B, Å D, et al. Structured postoperative physiotherapy in patients with cervical radiculopathy: outcomes at 6 months in a randomized clinical trial. J Neurosurg Spine Accepted 2017.

21. Wibault J, Öberg B, Dedering $\AA$, et al. Neck-related physical function, self-efficacy, and coping strategies in patients with cervical radiculopathy: a randomized clinical trial of postoperative physiotherapy. J Manipulative Physiol Ther 2017;40:330-9.

22. Cuijpers $P$, van Straten A, Andersson G. Internet-administered cognitive behavior therapy for health problems: a systematic review. J Behav Med 2008;31:169-77.

23. Sjöström M, Umefjord $G$, Stenlund $H$, et al. Internet-based treatment of stress urinary incontinence: a randomised controlled study with focus on pelvic floor muscle training. BJU Int 2013;112:362-72.

24. Revenäs $\AA$, Opava $\mathrm{CH}$, Ahlén $\mathrm{H}$, et al. Mobile internet service for selfmanagement of physical activity in people with rheumatoid arthritis: evaluation of a test version. RMD Open 2016;2:e 000214

25. Andersson $\mathrm{G}$. Using the Internet to provide cognitive behaviour therapy. Behav Res Ther 2009;47:175-80.

26. Garg S, Garg D, Turin TC, et al. Web-based interventions for chronic back pain: a systematic review. J Med Internet Res 2016;18:e139.

27. Shukla H, Nair SR, Thakker D. Role of telerehabilitation in patients following total knee arthroplasty: Evidence from a systematic literature review and meta-analysis. J Telemed Telecare 2017;23:339-46.

28. Bring A, Åsenlöf $P$, Söderlund A. What is the comparative effectiveness of current standard treatment, against an individually tailored behavioural programme delivered either on the Internet or face-to-face for people with acute whiplash associated disorder? A randomized controlled trial. Clin Rehabil 2016;30:441-53.

29. Lelieveld OT, Armbrust W, Geertzen JH, et al. Promoting physical activity in children with juvenile idiopathic arthritis through an internet-based program: results of a pilot randomized controlled trial. Arthritis Care Res 2010;62:697-703.

30. Vernon H, Mior S. The Neck Disability Index: a study of reliability and validity. J Manipulative Physiol Ther 1991;14:409-15.

31. MacDermid JC, Walton DM, Avery S, et al. Measurement properties of the neck disability index: a systematic review. J Orthop Sports Phys Ther 2009;39:400-C12.

32. Ludvigsson ML, Peterson G, Dedering $\AA$, et al. One- and twoyear follow-up of a randomized trial of neck-specific exercise with or without a behavioural approach compared with prescription of physical activity in chronic whiplash disorder. $J$ Rehabil Med 2016;48:56-64

33. Ludvigsson ML, Peterson G, O'Leary S, et al. The effect of neckspecific exercise with, or without a behavioral approach, on pain, disability, and self-efficacy in chronic whiplash-associated disorders: a randomized clinical trial. Clin J Pain 2015;31:294-303.

34. Gross AR, Paquin JP, Dupont G, et al. Exercises for mechanical neck disorders: a cochrane review update. Man Ther 2016;24:25-45.

35. Sarig-Bahat $H$. Evidence for exercise therapy in mechanical neck disorders. Man Ther 2003;8:10-20.

36. Kay TM, Gross A, Goldsmith $\mathrm{CH}$, et al. Exercises for mechanical neck disorders. Cochrane Database Syst Rev 2012:CD004250.

37. Gross AR, Goldsmith C, Hoving JL, et al. Conservative management of mechanical neck disorders: a systematic review. J Rheumatol 2007;34:1083-102.

38. Miller J, Gross A, D'Sylva J, et al. Manual therapy and exercise for neck pain: a systematic review. Man Ther 2010;15:334-54.

39. Geneen LJ, Moore RA, Clarke C, et al. Physical activity and exercise for chronic pain in adults: an overview of Cochrane reviews (review). http://onlinelibrary.wiley.com/doi/10.1002/14651858.CD011279. pub3/epdf

40. Swedish Council on Health Technology Assessment (SBU). Back pain, Neck pain. An evidence based review. (In Swedish) (Ont i ryggen, ont i nacken: en evidensbaserad kunskapssammanställning. Stockholm: SB Offsett AB, 2000. Nr 145/2, chapter 14-17.

41. Final Report. The Whiplash commission final report. http://www. whiplashkommissionen.se/www.whiplashkommissionen.se/pdf/WK finalreport.pdf

42. Kallings LV, Leijon ME, Kowalski J, et al. Self-reported adherence: a method for evaluating prescribed physical activity in primary health care patients. J Phys Act Health 2009;6:483-92. 
43. Leijon ME, Bendtsen P, Nilsen P, et al. Does a physical activity referral scheme improve the physical activity among routine primary health care patients? Scand J Med Sci Sports 2009;19:627-36

44. Carlsson AM. Assessment of chronic pain. I. Aspects of the reliability and validity of the visual analogue scale. Pain 1983;16:87-101.

45. Ferreira-Valente MA, Pais-Ribeiro JL, Jensen MP. Validity of four pain intensity rating scales. Pain 2011;152:2399-404.

46. Barbero M, Moresi F, Leoni D, et al. Test-retest reliability of pain extent and pain location using a novel method for pain drawing analysis. Eur J Pain 2015;19:1129-38.

47. Odom GL. Cervical disk lesions. J Am Med Assoc 1958;166:23-8.

48. Jacobson GP, Newman CW. The development of the Dizziness Handicap Inventory. Arch Otolaryngol Head Neck Surg 1990;116:424-7.

49. Yang M, Rendas-Baum R, Varon SF, et al. Validation of the Headache Impact Test (HIT-6 $\left.{ }^{\mathrm{TM}}\right)$ across episodic and chronic migraine. Cephalalgia 2011;31:357-67.

50. Osman A, Barrios FX, Gutierrez PM, et al. The pain catastrophizing scale: further psychometric evaluation with adult samples. J Behav Med 2000;23:351-65.

51. Altmaier ERD, Kao C, Lehmann T, et al. Role of self-efficacy in rehabilitation outcome among chronic low back pain patients. $J$ Counsel Psychol 1993;36:725-33.

52. Stratford P. Assessing disability and change on individual patients: a report of a patient specific measure. Physiotherapy Canada 1995;47:258-63.

53. Waddell G, Newton M, Henderson I, et al. A Fear-Avoidance Beliefs Questionnaire (FABQ) and the role of fear-avoidance beliefs in chronic low back pain and disability. Pain 1993;52:157-68.

54. Dedering A, Börjesson T. Assessing fear-avoidance beliefs in patients with cervical radiculopathy. Physiother Res Int 2013;18:193-202.

55. Zigmond AS, Snaith RP. The hospital anxiety and depression scale. Acta Psychiatr Scand 1983;67:361-70.

56. Brooks R. EuroQol: the current state of play. Health Policy 1996;37:53-72.

57. Tuomi K, Ilmarinen J, Jahkola A, et al. Helsinki: Finnish Institute of Occupational Health. 1998 https://academic.oup.com/occmed/ article/57/2/160/1584972/The-Work-Ability-Index-WAI.

58. Radkiewich P, Widerszal-Bazyl M. Psychometric Properties of work ability index in the light of comparative survey study. International Congress Series 2005:1289-304.

59. de Zwart BC, Frings-Dresen MH, van Duivenbooden JC. Testretest reliability of the Work Ability Index questionnaire. Occup Med 2002;52:177-81.

60. Siegrist J, Starke D, Chandola T, et al. The measurement of effortreward imbalance at work: European comparisons. Soc Sci Med 2004;58:1483-99.
61. Koopman C, Pelletier KR, Murray JF, et al. Stanford presenteeism scale: health status and employee productivity. J Occup Environ Med 2002;44:14-20

62. Turpin RS, Ozminkowski RJ, Sharda CE, et al. Reliability and validity of the Stanford Presenteeism Scale. J Occup Environ Med 2004;46:1123-33.

63. Statistics Sweden (SCB). SSYK 2012 Standard för svensk yrkesklassificering. 2012. In Swedish). (Devoloped from the ISCO-08 (International Standard Classification of Occupation $2008 \mathrm{http}: / /$ www.scb.se/statistik/_publikationer/OV9999_2012A01_BR X70BR1201.pdfhttp://www.ilo.org/public/english/bureau/stat/isco/ isco88/index.htm

64. Cherkin DC, Deyo RA, Street JH, et al. Predicting poor outcomes for back pain seen in primary care using patients' own criteria. Spine 1996:21:2900-7.

65. Howie JG, Heaney DJ, Maxwell M, et al. A comparison of a Patient Enablement Instrument (PEI) against two established satisfaction scales as an outcome measure of primary care consultations. Fam Pract 1998;15:165-71.

66. Ekberg K, Noorlind-Brage H, Dastserri M. Östgötens hälsa och miljö 2000. Swedish: Linköping: Folkhälsovetenskapligt Centrum Landstinget i Östergötland, 2000.

67. Peolsson A, Almkvist C, Dahlberg C, et al. Age- and sex-specific reference values of a test of neck muscle endurance. $J$ Manipulative Physiol Ther 2007;30:171-7.

68. Peolsson A, Hedlund R, Ertzgaard S, et al. Intra-and inter-tester reliability and age- and sex-specific range of motion of the neck. Physiother Canada 2000;52:233-42.

69. Jull GA, O'Leary SP, Falla DL. Clinical assessment of the deep cervical flexor muscles: the craniocervical flexion test. J Manipulative Physiol Ther 2008;31:525-33.

70. Wainner RS, Fritz JM, Irrgang JJ, et al. Reliability and diagnostic accuracy of the clinical examination and patient self-report measures for cervical radiculopathy. Spine 2003;28:52-62.

71. Peolsson A, Hedlund R, Oberg B. Intra- and inter-tester reliability and reference values for hand strength. J Rehabil Med 2001;33:36-41.

72. Kammerlind A-S, Bergquist Larsson P, Ledin T, et al. Reliability of clinical balance tests and subjective ratings in dizziness and disequilibrium. Adv Physiother 2005;7:96-107.

73. Peolsson A, Landén Ludvigsson M, Tigerfors AM, et al. Effects of neck-specific exercises compared to waiting list for individuals with chronic whiplash-associated disorders: a prospective, randomized controlled study. Arch Phys Med Rehabil 2016;97:189-95.

74. Landén Ludvigsson M, Peolsson A, Peterson G, et al. Neck-specific exercise is cost-effective in the treatment of chronic whiplash associated disorders. Analyses of a randomized clinical trial Medicine 2017;96:e7274.

75. Fox CS, Hwang SJ, Nieto K, et al. Digital connectedness in the framingham heart study. J Am Heart Assoc 2016;5:e003193. 